\title{
Spatial Pattern of Strawberry Powdery Mildew (Podosphaera aphanis) and Airborne Inoculum
}

H. Van der Heyden, M. Lefebvre, L. Roberge, and L. Brodeur, Compagnie de Recherche Phytodata inc., 111 Rang Saint-Patrice, Sherrington, Quebec, J0L 2N0, Canada; and O. Carisse, Agriculture and Agri-Food Canada, 430 Gouin Boulevard, St-Jean-surRichelieu, Quebec, Canada J3B 3E6, Canada

\begin{abstract}
Van der Heyden, H., Lefebvre, M., Roberge, L., Brodeur, L., and Carisse, O. 2014. Spatial pattern of strawberry powdery mildew (Podosphaera aphanis) and airborne inoculum. Plant Dis. 98:43-54.

The relationship between strawberry powdery mildew and airborne conidium concentration (ACC) of Podosphaera aphanis was studied using data collected from 2006 to 2009 in 15 fields, and spatial pattern was described using 2 years of airborne inoculum and disease incidence data collected in fields planted with the June-bearing strawberry (Fragaria $\times$ ananassa) cultivar Jewel. Disease incidence, expressed as the proportion of diseased leaflets, and ACC were monitored in fields divided into $3 \times 8$ grids containing $24100 \mathrm{~m}^{2}$ quadrats. Variance-tomean ratio, index of dispersion, negative binomial distribution, Poisson distribution, and binomial and beta-binomial distributions were used to characterize the level of spatial heterogeneity. The relationship between percent leaf area diseased and daily ACC was linear, while the relationship between ACC and disease incidence followed an exponential growth curve. The V/M ratios were significantly greater than 1 for 100 and $96 \%$ of the sampling dates for ACC sampled at $0.35 \mathrm{~m}$ from the ground $\left(\mathrm{ACC}_{0.35 \mathrm{~m}}\right)$ and for ACC sampled at $1.0 \mathrm{~m}$ from the ground $\left(\mathrm{ACC}_{1.0 \mathrm{~m}}\right)$, respectively. For disease incidence, the index of dispersion $D$ was significantly greater than 1 for $79 \%$ of the sampling dates. The negative binomial distribution fitted $86 \%$ of the data sets for

both $\mathrm{ACC}_{1.0 \mathrm{~m}}$ and $\mathrm{ACC}_{035 \mathrm{~m}}$. For disease incidence data, the beta-binomial distribution provided a good fit of $75 \%$ of the data sets. Taylor's power law indicated that, for ACC at both sampling heights, heterogeneity increased with increasing mean ACC, whereas the binary form of the power law suggested that heterogeneity was not dependent on the mean for disease incidence. When the spatial location of each sampling location was taken into account, Spatial Analysis by Distance Indices showed low aggregation indices for both ACCs and disease incidence, and weak association between ACC and disease incidence. Based on these analyses, it was found that the distribution of strawberry powdery mildew was weakly aggregated. Although a higher level of heterogeneity was observed for airborne inoculum, the heterogeneity was low with no distinct foci, suggesting that epidemics are induced by well-distributed inoculum. This low level of heterogeneity allows mean airborne inoculum concentration to be estimated using only one sampler per field with an overall accuracy of at least 0.841 . The results obtained in this study could be used to develop a sampling scheme that will improve strawberry powdery mildew risk estimation.
\end{abstract}

Strawberry powdery mildew, caused by the obligate parasite Podosphaera aphanis (Wallr.), is an important disease in numerous production areas in North America (17). In Canada, 4,112 ha of strawberry (Fragaria $\times$ ananassa (L.) Duch.) fields are harvested annually, mostly in the provinces of Quebec (44\%), Ontario (29\%), and British Columbia (7\%) (23). Several of the most commonly grown strawberry cultivars are susceptible to powdery mildew $(5,20)$, which can affect all aerial parts of the strawberry plant. Although powdery mildew symptoms vary with cultivar, the most common symptoms are small patches of white colonies that appear most often on the underside of the leaves. Under favorable conditions, the colonies increase in size and may coalesce and cover the entire leaf or aerial part of the plant. Severe foliar infections may induce premature leaf drop (1). Infected flowers may fail to produce fruits, and fruits infected at an early stage of maturation may fail to ripen (4).

The disease causes direct economic losses by reducing fruit set because of contaminated pollen, reducing the number of fruits that reach maturity (premature fruit drop), and reducing the number of fruits that are harvested because of the presence of white mycelia. Direct losses are generally more severe in day-neutral cultivars,

Corresponding author: O. Carisse, E-mail: odile.carisse@agr.gc.ca

* The $\boldsymbol{e}$-Xtra logo stands for "electronic extra" and indicates that Figures 7 and 8 appear in color online.

Accepted for publication 7 May 2013.

http://dx.doi.org/10.1094/PDIS-10-12-0946-RE

(C) 2014 Department of Agriculture and Agri-Food, Government of Canada because their fruits are produced over a long period (9), generally from mid-July to the end of September (which is when epidemics are generally severe), as well as in strawberry plants grown under plastic tunnels, because the weather conditions in tunnels are generally favorable to disease development $(5,22,26)$. The disease also causes indirect losses through leaf infection by reducing the photosynthetic potential of leaves and, hence, reducing plant vigor. Moreover, leaf infection by powdery mildew may reduce winter survival of Junebearing cultivars, which are grown over a 3 -year period $(2,17)$.

Although fungicide applications are generally required each year on field-grown day-neutral strawberry plants and on both dayneutral and June-bearing cultivars grown under plastic tunnels, the management of strawberry powdery mildew on field-grown Junebearing cultivars is more complex. In these crops, yield losses are significant only when disease onset is early in the season, when a high amount of airborne conidia coincides with the presence of flowers and young berries (4). Considering that young leaves are highly susceptible and that susceptibility decreases as leaves age, there are two critical periods: early in the season from bud break to flowering, and during the postharvest period (renovation) (4). In the absence of knowledge about the effect of late leaf infection by $P$. aphanis, growers apply fungicides during renovation to maintain plant vigor and reduce inoculum carryover (2). Tools are thus needed to guide disease management decisions during the postharvest period so that unnecessary fungicide applications can be avoided.

$P$. aphanis overwinters as cleistothecia produced in the fall on infected leaves or as mycelia in the crown (12). In spring, at the time of regrowth on June-bearing cultivars, the disease can be initiated by ascospores produced in cleistothecia or by conidia produced on mycelia that survived the winter (12). Secondary cycles are initiated by conidia produced on $P$. aphanis colonies and are responsible for disease progress during the growing season (3). 
The development of powdery mildew is favored by a wide range of weather conditions $(1,19,22)$. Because strawberry powdery mildew occurs under such a wide range of temperatures and relative humidity levels, predicting the risk of infection by $P$. aphanis from weather conditions is difficult. Therefore, the inclusion of information on airborne conidium concentration (ACC) and disease incidence could improve strawberry powdery mildew management decisions. In general, data from sampling improves grower's perception of risk. Knowledge of spatial and temporal structure of an epidemic is crucial for the development of sound sampling strategies. Such information is not available for strawberry powdery mildew $(3,4,6)$.

The first objective of this study was to establish the relationship between airborne $P$. aphanis inoculum concentration and both severity and incidence of strawberry powdery mildew. The second objective was to characterize the spatiotemporal structure of strawberry powdery mildew epidemics derived from ACC measured at two heights and from disease incidence. The third objective was to quantify the spatiotemporal association between ACC and strawberry powdery mildew incidence. A final objective was to evaluate the reliability of using only one sampler per field to assess ACC under commercial conditions.

\section{Materials and Methods}

Relationship between airborne inoculum concentration and powdery mildew severity. Sites and data collection. Data were collected from 2006 to 2009 at the Agriculture and Agri-Food Canada experimental farm located in Frelighsburg and at a commercial strawberry farm located in St-Paul-d'Abbotsford, Quebec, Canada. Data were collected in a total of 15 fields (4 at Frelighsburg and 11 at St-Paul-d'Abbotsford) planted with the June-bearing strawberry cultivar Jewel during the first or second year of production. The plots were $30 \mathrm{~m}$ long with 15 double rows distanced by $1.4 \mathrm{~m}$, and within rows plants were planted $30 \mathrm{~cm}$ apart. At all sites, fungicides were applied to manage gray mold caused by Botrytis cinerea. Fungicides used include pyraclostrobin + boscalid, fenhexamid, and iprodione. Powdery mildew management practices varied between farms, but in general, fungicides were not applied before renovation unless the disease was problematic the previous year. However, fungicides were applied after harvest in August or September.

Disease assessments were performed weekly from mid-June to mid-September on 25 strawberry plants selected randomly from each plot. Foliar powdery mildew was assessed on the three youngest fully expanded leaves per plant as the percent leaflets area diseased, using a diagrammatic scale with $5 \%$ steps $(0,5,10$, $15 \ldots 100 \%$ ) and expressed as the mean over all 25 plants. Powdery mildew incidence (I) was derived from the severity data by rating a leaflet as diseased if severity was $>0$. Incidence was calculated as the proportion of diseased leaflets over all 25 plants. ACC was monitored weekly using two rotating-arm impaction spore samplers (Compagnie de Recherche Phytodata Inc., Sherrington, QC, Canada) placed in the center of each plot at $0.35 \mathrm{~m}$ above the ground. Each sampler consisted of two $1.65 \times 20 \mathrm{~mm}$ vertical rods placed $83 \mathrm{~mm}$ apart and rotated at a constant speed of 2,400 rpm. Airborne particles were collected on the leading edge of the rods, each of which was coated with a thin layer of silicone grease (Fisher Scientific Company, Ottawa, ON, Canada). The effective sampling rate was 20.65 liters of air per minute. The samplers ran $30 \%$ of the time from 10 A.M. to 4 P.M., for a total of $2 \mathrm{~h}$ per sampling day. This sampling period was selected because $P$. aphanis ACC usually reaches a peak between 1 P.M. and 3 P.M. (3). After exposure, the rods were kept at $4^{\circ} \mathrm{C}$ and the number of conidia was counted under a microscope at $\times 250$ magnification within 1 week. The counts were transformed into conidia per cubic meter of air sampled $(4,7)$.

Data analysis. The relationship between ACC and powdery mildew severity was modeled with linear ordinary least-squares regression analyses as ACC $=\beta_{0}+\beta_{1} \times$ PLAD, where ACC is daily airborne conidia concentration, PLAD is percent leaf area diseased, $\beta_{0}$ is the intercept, and $\beta_{1}$ is the slope parameter. The relationship between ACC and powdery mildew incidence (I) was modeled using nonlinear regression and exponential growth model of the form ACC $=a \times e^{(b 1)}$, where $a$ and $b$ are regression parameters. The analyses were performed with the GLM and NLIN procedures of SAS (Version 9.3, SAS Institute Inc., Cary, NC).

Spatial pattern of strawberry powdery mildew. Sites and data collection. The experiment was conducted in two commercial strawberry fields planted in the spring of 2010 and 2011, in the southeast region of the province of Quebec, Canada $\left(45^{\circ} 37^{\prime} 10^{\prime \prime} \mathrm{N}\right.$; $\left.72^{\circ} 57^{\prime} 30^{\prime \prime} \mathrm{W}\right)$. The selected fields measured $51 \times 100 \mathrm{~m}$ and were planted in the year of the experiment with the June-bearing cultivar Jewel. The rows were spaced $1.4 \mathrm{~m}$ apart, and the plants were 30 $\mathrm{cm}$ apart within rows. The fields were divided into $3 \times 8$ grids containing 24 quadrats each measuring $100 \mathrm{~m}^{2}$. The experiment was conducted from 22 July to 9 September in 2010 and from 24 July to 22 September in 2011. Data were collected twice weekly for a total of 14 sampling dates each year.

To measure ACC, two spore samplers were placed in the middle of each quadrat, one at $0.35 \mathrm{~m}$ above the ground and the other at $1.0 \mathrm{~m}$ above the ground, for a total of 24 samplers per sampling height. Airborne conidium concentration was estimated as described above. Disease incidence was assessed by evaluating the number of leaflets infected by $P$. aphanis on five plants per quadrat and was expressed as the proportion of diseased leaflet. For each sampling date, disease incidence was assessed on the three youngest fully expanded leaves on the same five plants randomly selected at the first sampling date, and expressed as the proportion of diseased leaflets.

Temporal analysis. For both years, the temporal progress of $\mathrm{ACC}$ at $0.35 \mathrm{~m}$ above the ground $\left(\mathrm{ACC}_{0.35 \mathrm{~m}}\right), \mathrm{ACC}$ at $1.0 \mathrm{~m}$ above the ground $\left(\mathrm{ACC}_{1.0 \mathrm{~m}}\right)$, and disease incidence were described using the following sigmoid model:

$$
y=\frac{a}{\left\{1+\exp \left[\frac{-\left(x-x_{0}\right)}{b}\right]\right\}}
$$

where $y$ is the cumulative $\mathrm{ACC}_{0.35 \mathrm{~m}}, \mathrm{ACC}_{1.0 \mathrm{~m}}$, or disease incidence:

$$
\left(\sum_{i}^{n} y_{i}, n=14\right) \text {, }
$$

$a$ is the asymptote, $b$ is the slope of the linear portion of the sigmoid curve, and $x_{0}$ represents the time at which $y$ is one-half of the maximum. For the purposes of measuring the accuracy of model fit, sum of squared error (SSE), root mean squares error (RMSE), and coefficients of determination $\left(R^{2}\right)$ were considered.

Spatial analysis: aggregation indices. For ACC data, the variance-to-mean (V/M) ratio was used to explore spatial heterogeneity. For each sampling date, the ratio was calculated by dividing the observed sample variance by the observed sample mean. The spatial pattern was considered to be regular, completely random, or aggregated if the V/M ratio was smaller than 1 , strictly equal to 1 , or greater than 1 , respectively $(11,18)$. If there is a random distribution, $(n-1) \times \mathrm{V} / \mathrm{M}$ follows a $\chi^{2}$ distribution with $(n-1)$ degrees of freedom, where $n$ is sample size. For disease incidence, the index of dispersion, $D$, was used to detect departure from randomness. This index is a ratio of two variances; the observed variance and the variance estimated under the assumption of a binomial distribution (18) is expressed as:

$$
D=\frac{s_{y}^{2}}{\bar{y}(1-\bar{y}) / n}
$$

where $s_{y}^{2}$ is the observed variance and $\bar{y}(1-\bar{y}) / n$ is the binomial variance. A value of $D$ equal to 1 indicates that the two variances are equal, indicative of a random pattern within sampling unit. A value of $D$ greater than 1 indicates a departure from a complete random patter indicating heterogeneity at the scale of the sampling unit. If there is a random distribution, $(n-1) \times D$ follows a $\chi^{2}$ distribution with $(n-1)$ degrees of freedom, where $n$ is sample size (18). 
Spatial analysis: distribution analysis. For ACC data at each sampling date, the negative binomial and Poisson distributions were fitted to the data using the NLMIXED procedure in the SAS software program (v9.3; SAS Institute). The negative binomial distribution has two parameters: $\mu$, which represents the sample mean, and $\kappa$, which is a measure of heterogeneity among sampling units. The Poisson distribution has a single parameter, $\mu$, which represents the sample mean. A good fit of the Poisson distribution is an indication of a completely random pattern, whereas a good fit of the negative binomial distribution is an indication of an aggregated spatial pattern. The negative binomial parameter $\kappa$ is used as a clustering index. As $\kappa$ approaches 0 , the level of aggregation increases. Conversely, when $\kappa$ increases, the negative binomial distribution approaches the Poisson distribution. The goodness of fit for each distribution was estimated using a likelihood ratio test (18).

For disease incidence, the binomial and beta-binomial distributions were fitted to the data for each sampling date. The binomial distribution has two parameters, $n$ and $p$, representing the number of samples in each $N$ sampling unit and the probability of a leaflet being diseased, respectively $(11,18,24)$. The beta-binomial distribution has three parameters, $n, p$, and $\theta$, which are the number of samples in each $N$ sampling unit, the probability of a leaflet being diseased, and a heterogeneity parameter, respectively $(11,18)$. Heterogeneity increases with increasing $\theta$, and conversely, when $\theta$ approaches 0 the beta-binomial approaches the binomial distribution. A good fit of the binomial distribution is an indication of a completely random pattern, whereas a good fit of the beta-binomial distribution is an indication of an aggregated spatial pattern (18).
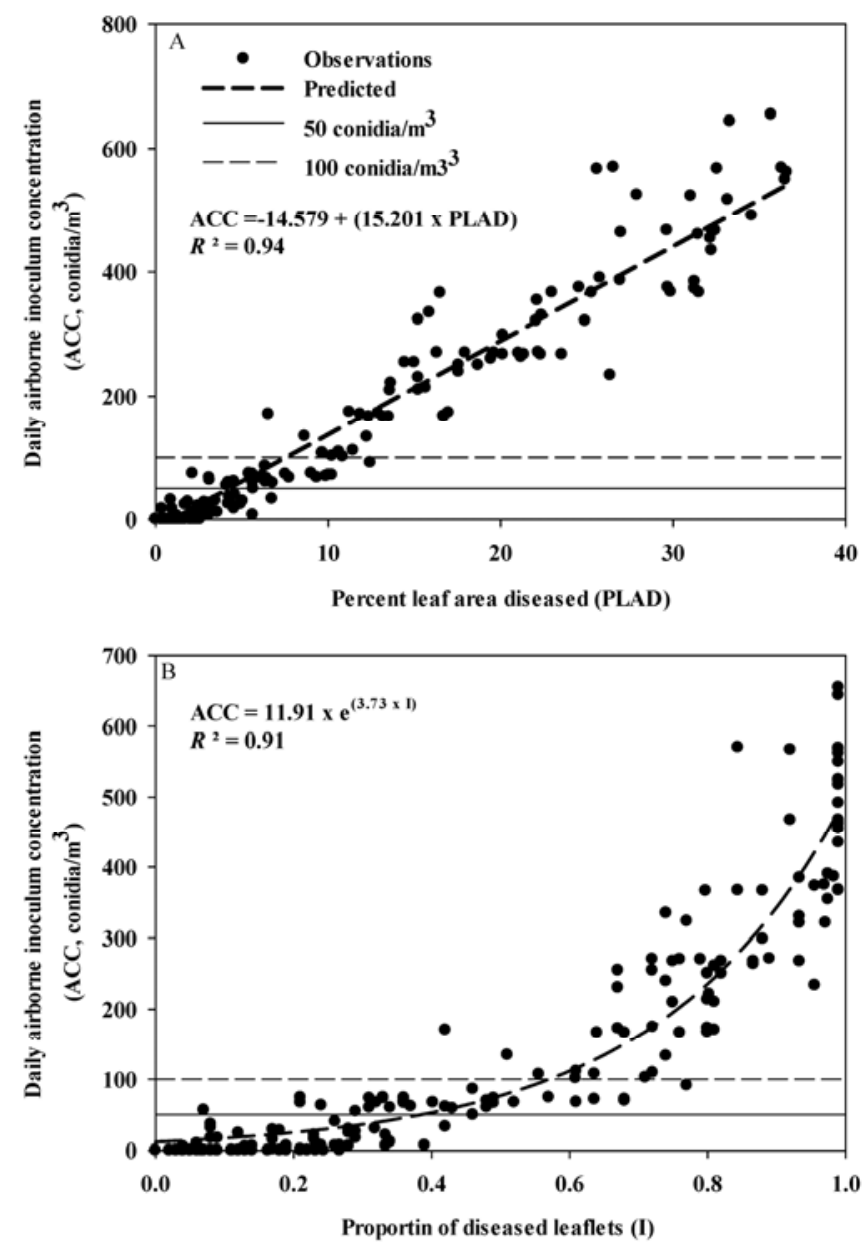

Fig. 1. Relationship between percent leaf area diseased (PLAD) and Podosphaera aphanis airborne conidium concentration (ACC). A total of 252 observations were used in the regression analysis, and each point represents the mean PLAD over all 25 plants per plot and ACC measured with one sampler per plot.
The goodness of fit for each distribution was estimated using a likelihood ratio test (18).

Spatial analysis: power law relationship. Power law relationships were used to quantify heterogeneity among ACC and disease incidence from different sampling dates. In this case, instead of assessing the degree of aggregation related to a distribution for each sampling date individually, the power law was used to characterize heterogeneity among sampling dates in order to determine if heterogeneity increased with increasing means. The power law describes the relationship between the observed variance $\left(S_{o b s}^{2}\right)$ and the observed mean $(\bar{Y})$. The equation is written as follows:

$$
S_{o b s}^{2}=A \bar{Y}^{b}
$$

Taking the natural logarithm of both sides of equation 3 yields the following equation:

$$
\ln S_{o b s}^{2}=\ln (A)+b \ln (\bar{Y})
$$

The intercept $(\ln (A))$ and slope $(b)$ parameters were estimated by linear regression analysis. For disease incidence, the binary form of Taylor's power law was used to characterize heterogeneity. In this form, the power law is expressed as a relationship between the observed variance and the binomial variance:

$$
\ln \left(V_{\text {obs }}\right)=\ln \left(A_{x}\right)+b \ln [\bar{y}(1-\bar{y}) / n]
$$

in which $V_{o b s}$ is the observed variance and $\bar{y}(1-\bar{y}) / n$ is the binomial variance. When $A$ or $A_{x}$ and $b$ are both strictly equal to 1 , it

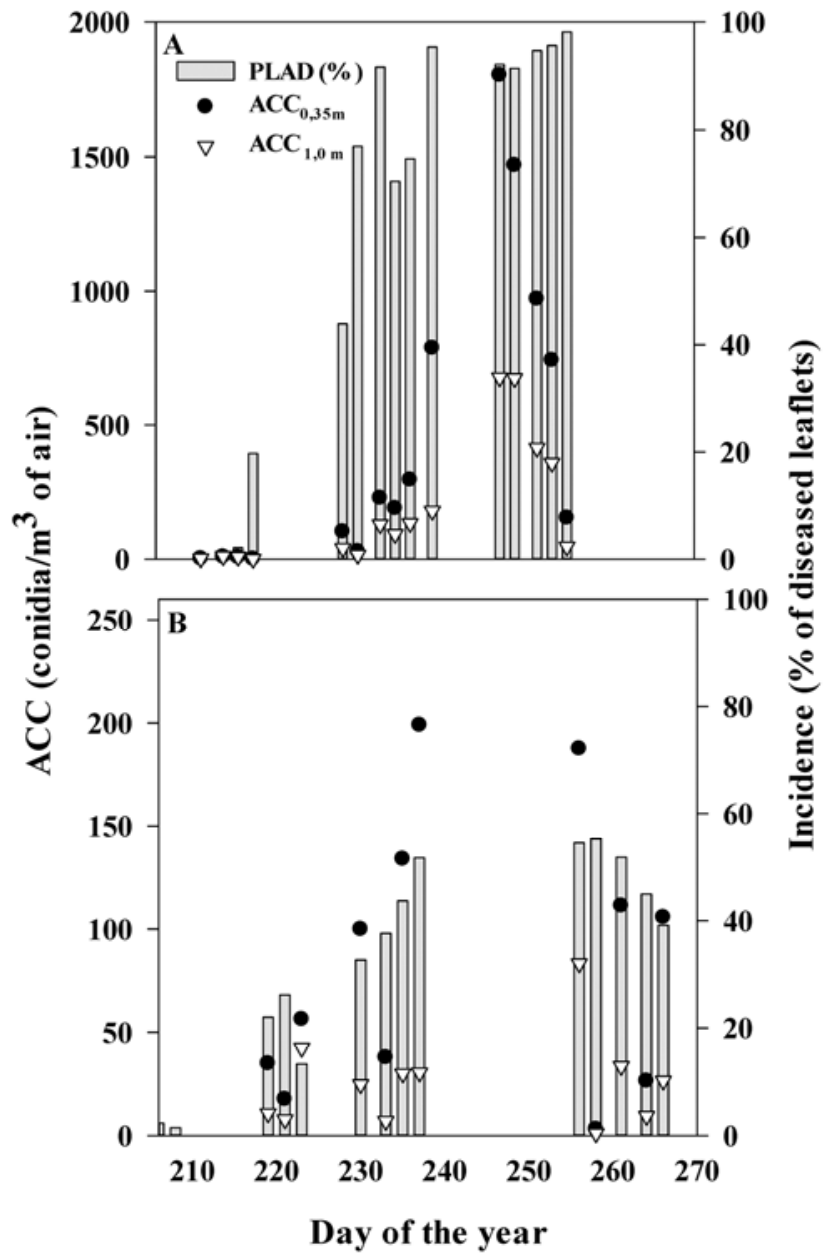

Fig. 2. Description of the epiphytic of strawberry powdery mildew caused by Podosphaera aphanis in A, 2010 and B, 2011. Gray bars represent disease incidence expressed as percent diseased leaflets, black circles represent airborne conidia concentration at $0.35 \mathrm{~m}$ above the ground $\left(\mathrm{ACC}_{0.35 \mathrm{~m}}\right)$, and open triangles represent $A C C$ at $1.0 \mathrm{~m}$ above the ground $\left(\mathrm{ACC}_{1.0 \mathrm{~m}}\right)$. 
can be concluded that there is a completely random pattern. When $A$ or $A_{x}$ is greater than 1 and $b$ is equal to 1 , the spatial pattern is aggregated, but the level of aggregation is not directly influenced by the mean. If $A$ or $A_{x}$ and $b$ are both greater than 1 , the spatial pattern is considered to be aggregated, and the aggregation is directly related to the mean $(7,13,14,18,24,25)$. The significance of the estimated parameters was determined with a $t$ test, and goodness-of-fit was evaluated using the coefficient of determination $\left(R^{2}\right)$. A covariance analysis was conducted to measure the effect of the year of sampling on the intercept and the interaction between the year and slope parameters of equations 4 and 5. For ACC, a covariance analysis was also used to test the effect of the sampling height using pooled data (2010 and 2011). The regression and covariance analysis were performed using the GLM procedure of SAS.

Spatial analysis: Spatial Analysis by Distance IndicEs. To consider the spatial location of the data, the spatial patterns of ACC and disease incidence were further analyzed with the Spatial Analysis by Distance Indices (SADIE) procedure. The SADIE procedure provides an alternative to the autocorrelation-based method and is based on the analysis of distance to regularity: the more a spatial pattern is aggregated, the more the distance to regularity
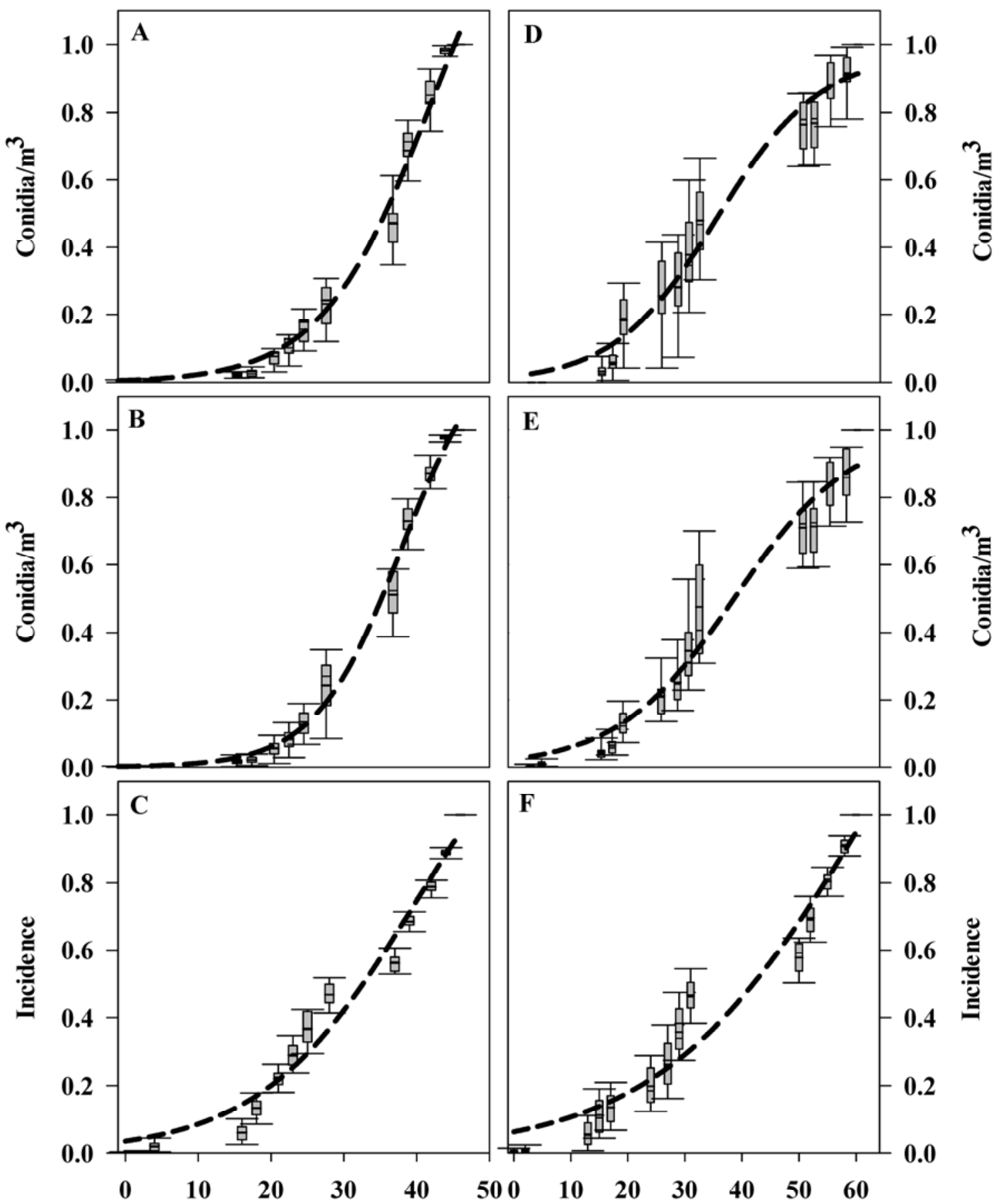

Days from the beginning of the epidemics

Fig. 3. Box plots summarizing spatial variation of cumulative airborne conidium concentration at $1.0 \mathrm{~m}$ above the ground $\left(\mathrm{ACC}_{1.0 \mathrm{~m}}\right)$, cumulative $\mathrm{ACC}$ at $0.35 \mathrm{~m}$ above the ground $\left(\mathrm{ACC}_{0.35 \mathrm{~m}}\right)$, and powdery mildew cumulative incidence expressed in terms of number of diseased leaflets in 2010 (A, B, and C, respectively) and 2011 (D, E, and F, respectively). Solid and broken lines within the box represent mean and median, respectively, and top and bottom lines of the box represent the 75 th and 25 th percentiles of the data, respectively. The bold line represents the adjusted sigmoid model. Parameter estimates of the sigmoid model are provided in Table 1. 
will be large (18). This analysis is based on the notion of distance to regularity, an approach that allows heterogeneity to be quantified by estimating the distance that a referenced sampling unit must be moved within a site so that the data are regular (16). The aggregation index $\left(I_{a}\right)$ was calculated as follows:

$$
I_{a}=D_{r} / E_{a}
$$

where $D_{r}$ is the distance to regularity and $E_{a}$ represents the average distance to regularity (24). For $I_{a}$, a value smaller than 1 characterizes a spatial pattern that is regular, a value strictly equal to $1 \mathrm{de}-$ scribes a completely random pattern, and a value greater than 1 suggests spatial heterogeneity. Similarly, the spatial association between ACC at both heights and incidence was evaluated using the procedure developed by Perry (21). The overall association index $(X)$ was estimated under the null hypothesis of lack of association; the procedure investigates the arrangement of the counts of both paired variables. A value of $X$ greater than 0 is an indication of spatial association $(7,24)$. A $\chi^{2}$ test was used to determine whether $I_{a}$ was significantly different from 1 , and Dutilleuladjusted randomizations (10) were used to test whether $X$ was significantly higher than 0 . Values for $I_{a}$ and $X$ were calculated using the freeware SADIEShell (v2.0).
Reliability of using one sampler to estimate ACC. To evaluate the reliability of using one sampler to assess ACC, a contingency table was built based on two $\mathrm{ACC}_{1.0 \mathrm{~m}}$ thresholds: 100 conidia $/ \mathrm{m}^{3}$ and 50 conidia $/ \mathrm{m}^{3}$. These thresholds were selected based on analysis of the relationship between airborne inoculum concentration and powdery mildew development (Fig. 1) and information available in the scientific literature $(3,4,6)$. For each sampling date, the mean ACC for each height was calculated as the mean ACC over the 24 samplers and considered as the true mean. For each sampling date, the ACC data for each sampler were divided into two groups: the cases and the controls (15). Cases were defined as the ACC values at or above the threshold, and the controls were defined as the values below the threshold. For each sampling height and each threshold, the true-positive proportion (TPP) was calculated by dividing the number of true positives (both ACC and mean ACC were above the threshold) by the total number of cases; the true-negative proportion (TNP) was calculated by dividing the number of true negatives (both ACC and mean ACC were below the threshold) by the total number of controls; the false-positive proportion (FPP) was calculated as 1 - TNP; and the false-negative proportion (FNP) was calculated as $1-$ TPP. Overall accuracy was calculated as the number of correct assess-

Table 1. Estimated parameters of the sigmoid model (equation 1) for Podosphaera aphanis airborne conidia concentration at $1.0 \mathrm{~m}\left(\mathrm{ACC}_{1.0 \mathrm{~m}}\right), 0.35 \mathrm{~m}$ $\left(\mathrm{ACC}_{0.35 \mathrm{~m}}\right)$, and for powdery mildew incidence for 2010 and 2011

\begin{tabular}{llccrcc}
\hline Year & Variables & $\boldsymbol{R}^{\mathbf{2}} \mathbf{a d j}$ & $\boldsymbol{a}(\mathbf{S E})^{\mathbf{a}}$ & $\boldsymbol{b}(\mathbf{S E})^{\mathbf{a}}$ & $\boldsymbol{X}_{\mathbf{0}}(\mathbf{S E})^{\mathbf{a}}$ & \multicolumn{1}{c}{$\boldsymbol{P}$} \\
\hline 2010 & ACC $_{1.0 \mathrm{~m}}$ & 0.99 & $1.65(0.31)$ & $7.38(0.85)$ & $42.04(0.09)$ & $<0.001$ \\
& ACC $_{0.35 \mathrm{~m}}$ & 0.99 & $1.30(0.11)$ & $5.83(0.55)$ & $38.16(1.28)$ & $<0.001$ \\
& Incidence $_{2011}$ & 0.97 & $1.49(0.51)$ & $10.73(2.34)$ & $40.03(7.86)$ & $<0.001$ \\
& ACC $_{1.0 \mathrm{~m}}$ & 0.98 & $0.97(0.07)$ & $9.44(1.80)$ & $34.15(2.73)$ & $<0.001$ \\
& ACC $_{0.35 \mathrm{~m}}$ & 0.99 & $1.01(0.13)$ & $10.88(2.46)$ & $37.56(4.70)$ & $<0.001$ \\
& Incidence & 0.96 & $2.00(1.64)$ & $18.03(5.41)$ & $61.84(27.20)$ & $<0.001$ \\
\hline
\end{tabular}

a Value of the estimate followed by value of its standard error in parentheses.

Table 2. Variance-to-mean ratios and associated statistics of the negative binomial and Poisson distributions fitted to data on Podosphaera aphanis airborne conidia concentration (ACC) and strawberry powdery mildew collected in 2010

\begin{tabular}{|c|c|c|c|c|c|c|c|}
\hline Variables & Date & $\mathbf{V} / \mathbf{M}^{\mathbf{a}}$ & $k^{\mathbf{b}}$ & $P^{c}$ & $\mu^{\mathrm{d}}$ & $P^{\mathbf{e}}$ & LRT $^{\mathbf{f}}$ \\
\hline \multirow[t]{14}{*}{$\mathrm{ACC}_{1.0 \mathrm{~m}}$} & 25 July & $3.42 *$ & 4.29 & 0.4180 & 11.40 & 0.0001 & 0 \\
\hline & 27 July & $4.73^{*}$ & 1.31 & 0.0208 & 10.11 & 0.0001 & 1.6 \\
\hline & 29 July & $3.41 *$ & 0.16 & 0.1479 & 2.82 & 0.0020 & -1 \\
\hline & 10 August & $9.62 *$ & 3.52 & 0.0071 & 43.08 & 0.0001 & $75.6^{* * * *}$ \\
\hline & 12 August & $21.06^{*}$ & 0.86 & 0.0023 & 17.32 & 0.0001 & $262.7 * * *$ \\
\hline & 15 August & $26.79^{*}$ & 2.63 & 0.0030 & 129.57 & 0.0001 & $595 * * *$ \\
\hline & 17 August & $15.39^{*}$ & 3.02 & 0.0062 & 97.32 & 0.0001 & $40.4 * * *$ \\
\hline & 19 August & $27.56^{*}$ & 3.12 & 0.0020 & 134.04 & 0.0001 & $636 * * *$ \\
\hline & 22 August & $54.75^{*}$ & 1.50 & 0.0014 & 179.58 & 0.0001 & $1,418.1 * * *$ \\
\hline & 31 August & $163.09 *$ & 1.15 & 0.0009 & 677.71 & 0.0001 & $5,288.2^{* * *}$ \\
\hline & 02 September & $141.17 *$ & 1.54 & 0.0024 & 705.82 & 0.0001 & $2,586.8 * * *$ \\
\hline & 05 September & $95.32 *$ & 1.88 & 0.0012 & 415.00 & 0.0001 & $2,815^{* * *}$ \\
\hline & 07 September & $74.12^{*}$ & 1.87 & 0.0013 & 358.67 & 0.0001 & $2,102.9 * * *$ \\
\hline & 09 September & $14.18^{*}$ & 2.01 & 0.0023 & 46.46 & 0.0001 & $308.1 * * *$ \\
\hline \multirow[t]{14}{*}{$\mathrm{ACC}_{0.35 \mathrm{~m}}$} & 25 July & $4.75^{*}$ & 2.27 & 0.0196 & 9.40 & 0.0001 & 0 \\
\hline & 27 July & $3.53^{*}$ & 2.29 & 0.0292 & 7.75 & 0.0001 & 0 \\
\hline & 29 July & $11.65^{*}$ & 0.18 & 0.6510 & 3.92 & 0.0001 & $29.7 * * *$ \\
\hline & 10 August & $53.89 *$ & 1.39 & 0.0019 & 102.48 & 0.0001 & 3.4 \\
\hline & 12 August & $30.92 *$ & 1.01 & 0.0014 & 37.37 & 0.0001 & $109.2 * * *$ \\
\hline & 15 August & $71.66^{*}$ & 1.74 & 0.0017 & 237.48 & 0.0001 & $114.3 * * *$ \\
\hline & 17 August & $44.53 *$ & 3.54 & 0.0020 & 189.54 & 0.0001 & $22.4 * * *$ \\
\hline & 19 August & $44.14^{*}$ & 1.04 & 0.0010 & 295.87 & 0.0001 & $192.4 * * *$ \\
\hline & 22 August & $248.74^{*}$ & 16.29 & 0.0020 & 788.33 & 0.0001 & $109.9 * * *$ \\
\hline & 31 August & $109.39 *$ & 12.06 & 0.0019 & $1,803.08$ & 0.0001 & $399.6^{* * *}$ \\
\hline & 02 September & $112.49 *$ & 0.46 & 0.0024 & $1,468.62$ & 0.0001 & -0.4 \\
\hline & 05 September & $260.20 *$ & 6.92 & 0.0017 & 971.08 & 0.0001 & $157.2 * * *$ \\
\hline & 07 September & $69.09 *$ & 9.12 & 0.0025 & 741.74 & 0.0001 & $138.4 * * *$ \\
\hline & 09 September & $25.17 *$ & 4.78 & 0.0024 & 153.79 & 0.0001 & $216.2 * * *$ \\
\hline
\end{tabular}

\footnotetext{
a $\mathrm{V} / \mathrm{M}$ is the variance-to-mean ratio. Values with an asterisk are significantly different from 1 based on a $\chi^{2}$ goodness-of-fit test.

${ }^{\mathrm{b}} k$ is a parameter of the negative binomial distribution representing a measure of heterogeneity.

${ }^{\mathrm{c}} P$ is the probability that $\kappa$ is different from 0 with $\alpha=0.05$.

$\mathrm{d} \mu$ is the mean estimated by the Poisson distribution.

e $P$ is the probability that $\mu$ is different from 0 with $\alpha=0.05$.

f Values of the likelihood ratio and level of significance according to a $\chi^{2}$ goodness-of-fit test $(* P<0.05 ; * * P<0.01 ; * * * P<0.001)$.
} 
ments $(\mathrm{TN}+\mathrm{TP})$ divided by the number of all assessment $(\mathrm{TN}+$ $\mathrm{TP}+\mathrm{FN}+\mathrm{FP})(15)$.

\section{Results}

The relationship between percent leaf area diseased and daily airborne conidium concentration (ACC) was linear (Fig. 1A). The linear regression explained a large proportion of the variation in ACC $\left(R^{2}=0.94\right)$. Base on this analysis, when the percent leaf area diseased ranged from 4 to $8 \%$, the predicted ACC values ranged from 61.4 to 137.4 conidia $/ \mathrm{m}^{3}$, respectively. Airborne conidium concentration (ACC) followed an exponential growth curve $\left(R^{2}=\right.$ 0.92) (Fig. 1B). Based on this analysis, when disease incidence ranged from 0.25 to 0.50 , the predicted $\mathrm{ACC}$ values ranged from 16.1 to 63.8 conidia $/ \mathrm{m}^{3}$, respectively. Considering that an action threshold for fungicide application of $5 \%$ leaf area diseased, which corresponds to disease incidence of 0.35 (5), was suggested to avoid damage to berries (6), we selected ACC thresholds of 50 and 100 conidia $/ \mathrm{m}^{3}$, which could be considered as warning and action threshold for postharvest treatments, respectively.

Overall, disease incidence and ACC were higher in 2010 than in 2011. Incidence varied in 2010 from 0 to a maximum of $98 \%$ diseased leaflets, which was reached on 1 September, and in 2011 from 0 to a maximum of $55 \%$ diseased leaflets, which was reached on 24 August (Fig. 2A and B). Airborne conidium concentrations measured at $0.35 \mathrm{~m}$ varied in 2010 from 1.3 conidia $/ \mathrm{m}^{3}$ to a maximum of 1,803 conidia $/ \mathrm{m}^{3}$, which was reached on 31 August, and in 2011 from 0 conidia $/ \mathrm{m}^{3}$ to a maximum of 198.7 conidia $/ \mathrm{m}^{3}$, which was reached on 25 August (Fig. 2A and B). Airborne conidium concentrations measured at $1.0 \mathrm{~m}$ ranged in 2010 from 0.68 conidia $/ \mathrm{m}^{3}$ to 677.71 conidia $/ \mathrm{m}^{3}$, and in 2011 from 1.08 conidia $/ \mathrm{m}^{3}$ to a maximum of $83.20 \mathrm{conidia} / \mathrm{m}^{3}$, which was reached on $19 \mathrm{Sep}-$ tember (Fig. 2A and B).

For both years and for all three variables $\left(\mathrm{ACC}_{1.0 \mathrm{~m}}, \mathrm{ACC}_{0.35 \mathrm{~m}}\right.$, and disease incidence), the progress curves were adequately explained by the three-parameter sigmoid model (Fig. 3) with $R^{2}$ values greater than 0.95 (Table 1). The disease progress curves were plotted with consideration given to spatial variation at each assessment date, and spatial variation is presented as error bars (Fig. 3).

In 2010, the V/M ratio for ACCs at both heights and for all sampling dates was significantly greater than 1 based on a $\chi^{2}$ test (Table 2). In 2011, the V/M ratio for ACCs at both heights and for all sampling dates was significantly greater than 1 based on a $\chi^{2}$ test, except on 15 September for $\mathrm{ACC}_{1.0 \mathrm{~m}}$ (Table 3). For disease incidence, the indices of dispersion $D$ were significantly greater than 1 for 8 of the 14 sampling dates in 2010, and greater than 1 for the 14 sampling dates in 2011 (Table 4; Fig. 4A and B; Fig. 5). Based on the $\mathrm{V} / \mathrm{M}$ ratios and index of dispersion $D, \mathrm{ACC}$ at both sampling heights and incidence were considered aggregated for most sampling dates.

For ACC, both years, and for all sampling dates it was possible to fit both the negative binomial and Poisson distributions (Tables 2 and 3 ). In 2010, based on the significance of the distribution parameters and on the likelihood ratio test, a better fit of the negative binomial distribution was obtained for 79 and $71 \%$ of the $\mathrm{ACC}_{1.0 \mathrm{~m}}$ and $\mathrm{ACC}_{0.35 \mathrm{~m}}$ sampling dates, respectively (Table 2). In 2011, a better fit of the negative binomial distribution compared to the Poisson distribution was obtained for 93 and $100 \%$ of the $\mathrm{ACC}_{1.0 \mathrm{~m}}$ and $\mathrm{ACC}_{0.35 \mathrm{~m}}$ sampling dates, respectively (Table 3; Fig. 4). For disease incidence, it was possible to fit the binomial and beta-binomial distributions over all the data sets in both 2010 and 2011 (Table 4). A better fit of the beta-binomial compared to the binomial distribution was obtained for 57 and $93 \%$ of the sampling dates in 2010 and 2011, respectively (Table 4). Even though the beta-binomial provided a better fit of the data for both years, the values of $\theta$ were relatively low, ranging from 0 to 0.34 in 2010 with a median value of 0.10 and ranging from 0.02 to 0.92 with a median value of 0.15 in 2011 (Fig. 5B and C). From the distribution analysis, it was concluded that, for both years at both heights, ACCs were spatially aggregated, while disease incidence was found to be weakly aggregated.

Based on the analysis of the pooled data (2010 and 2011), Taylor's power law provided a good fit to the ACC data at both

Table 3. Variance-to-mean ratios and associated statistics of the negative binomial and Poisson distributions fitted to data on Podosphaera aphanis airborne conidia concentration and strawberry powdery mildew collected in 2011

\begin{tabular}{|c|c|c|c|c|c|c|c|}
\hline Variables & Date & $\mathbf{V} / \mathbf{M}^{\mathbf{a}}$ & $k^{\mathbf{b}}$ & $P^{c}$ & $\mu^{\mathbf{d}}$ & $P^{\mathbf{e}}$ & LRT $^{f}$ \\
\hline \multirow[t]{12}{*}{$\mathrm{ACC}_{1.0 \mathrm{~m}}$} & 07 August & $4.88 *$ & 2.81 & 0.0189 & 11.24 & 0.0001 & -3.5 \\
\hline & 09 August & $4.04 *$ & 1.33 & 0.0168 & 9.35 & 0.0001 & $42.3 * * *$ \\
\hline & 11 August & $8.30^{*}$ & 5.27 & 0.0073 & 42.32 & 0.0001 & $17 * * *$ \\
\hline & 18 August & $12.51^{*}$ & 2.69 & 0.0232 & 27.20 & 0.0001 & $30.4 * * *$ \\
\hline & 21 August & $3.64 *$ & 2.64 & 0.0036 & 7.34 & 0.0001 & $1,054.1 * * *$ \\
\hline & 23 August & $12.67 *$ & 4.58 & 0.0052 & 29.91 & 0.0001 & $356.6^{* * *}$ \\
\hline & 25 August & $8.27 *$ & 4.25 & 0.0023 & 30.33 & 0.0001 & $1,574.8 * * *$ \\
\hline & 13 September & $22.40 *$ & 0.96 & 0.1661 & 83.21 & 0.0001 & $1,196.3 * * *$ \\
\hline & 15 September & 1.92 & 3.20 & 0.0040 & 1.81 & 0.0004 & $1,093.7 * * *$ \\
\hline & 18 September & $9.78 *$ & 0.70 & 0.0044 & 33.46 & 0.0001 & $7,003.8 * * *$ \\
\hline & 21 September & $16.45^{*}$ & 1.37 & 0.0065 & 11.40 & 0.0001 & $2,446.7 * * *$ \\
\hline & 23 September & $17.09 *$ & 1.64 & 0.0037 & 27.68 & 0.0001 & $2,597.9 * * *$ \\
\hline \multirow[t]{14}{*}{$\mathrm{ACC}_{0.35 \mathrm{~m}}$} & 25 July & $2.34 *$ & 2.76 & 0.0940 & 3.71 & 0.0001 & $4,128.4 * * *$ \\
\hline & 27 July & $5.09 *$ & 1.02 & 0.0131 & 6.69 & 0.0001 & $1,523.3 * * *$ \\
\hline & 07 August & $40.61 *$ & 1.33 & 0.0012 & 34.83 & 0.0001 & $522 * * *$ \\
\hline & 09 August & $12.89 *$ & 1.55 & 0.0025 & 17.58 & 0.0001 & $6.8 *$ \\
\hline & 11 August & $12.92 *$ & 4.00 & 0.0037 & 56.17 & 0.0001 & $29.6 * * *$ \\
\hline & 18 August & $142.59 *$ & 0.87 & 0.0006 & 99.92 & 0.0001 & $613.5 * * *$ \\
\hline & 21 August & $43.35^{*}$ & 1.60 & 0.0015 & 37.71 & 0.0001 & $198.4 * * *$ \\
\hline & 23 August & $251.38 *$ & 0.81 & 0.0007 & 134.00 & 0.0001 & $222.6 * * *$ \\
\hline & 25 August & $530.99 *$ & 0.64 & 0.0004 & 198.96 & 0.0001 & $2,599.7 * * *$ \\
\hline & 13 September & $42.93 *$ & 4.88 & 0.0019 & 187.50 & 0.0001 & $560 * * *$ \\
\hline & 15 September & $2.65^{*}$ & 2.01 & 0.0577 & 3.41 & 0.0001 & $3,856.9 * * *$ \\
\hline & 18 September & $62.42 *$ & 2.48 & 0.0014 & 111.21 & 0.0001 & $7,659.2 * * *$ \\
\hline & 21 September & $34.75^{*}$ & 0.74 & 0.0009 & 26.38 & 0.0001 & $825.6^{* * *}$ \\
\hline & 23 September & $24.58 *$ & 3.76 & 0.0021 & 105.67 & 0.0001 & $10.3 * *$ \\
\hline
\end{tabular}

\footnotetext{
a V/M is the variance-to-mean ratio. Values with an asterisk are significantly different from 1 based on a $\chi^{2}$ goodness-of-fit test.

${ }^{\mathrm{b}} k$ is a parameter of the negative binomial distribution representing a measure of heterogeneity.

${ }^{\mathrm{c}} P$ is the probability that $\kappa$ is different from 0 with $\alpha=0.05$.

${ }^{\mathrm{d}} \mu$ is the mean estimated by the Poisson distribution.

e $P$ is the probability that $\mu$ is different from 0 with $\alpha=0.05$.

${ }^{\mathrm{f}}$ Values of the likelihood ratio and level of significance according to a $\chi^{2}$ goodness-of-fit test $(* P<0.05 ; * * P<0.01$; *** $P<0.001)$.
} 
heights, with $R^{2}$ values of 0.97 and 0.96 for $\mathrm{ACC}_{1.0 \mathrm{~m}}$ and $\mathrm{ACC}_{0.35 \mathrm{~m}}$, respectively (Fig. 6). At both heights, the estimated slopes were significantly greater than $1(P<0.001)$, and the intercept parameter was significantly greater than 0 for $\operatorname{ACC}_{0.35 \mathrm{~m}}(P=0.021)$ but not for $\mathrm{ACC}_{1.0 \mathrm{~m}}(P=0.086)$. For disease incidence, the binary power law also provided a good fit, with a smaller $R^{2}$ value of 0.65 . The estimated slope was not significantly different from $1(P=0.520)$, but the intercept was significantly different from $0(P=0.007)$. Based on covariance analysis, the year of sampling had no significant effect on the intercept, with $P=0.453, P=0.079$, and $P=$ 0.778 for $\mathrm{ACC}_{1.0 \mathrm{~m}}, \mathrm{ACC}_{0.35 \mathrm{~m}}$, and disease incidence, respectively. The interaction between the year of sampling and the slope parameter was not significant for $\mathrm{ACC}_{1.0 \mathrm{~m}}$ and disease incidence, with $P=0.836$ and $P=0.163$, respectively. However, for $\mathrm{ACC}_{0.35 \mathrm{~m}}$, the interaction between the sampling year and the slope parameter was significant $(P=0.013)$.

The contour plots of the clustering index from the SADIE analyses for $\mathrm{ACC}_{1.0 \mathrm{~m}}, \mathrm{ACC}_{0.35 \mathrm{~m}}$, and disease incidence for 2010 and 2011 are displayed in Figures 7 and 8, respectively. For all variables and both years, the aggregation indices $I_{a}$ computed by SADIE varied from 0.75 to 2.04 , which is an indication of a weak spatial aggregation expressed by the presence of heterogeneity without distinct aggregates (Fig. 9A and C). The SADIE analysis also showed a significant overall positive association $(X)$ between $\mathrm{ACC}_{0.35 \mathrm{~m}}$ and incidence, given that $54 \%$ of the $X$ values were significantly different from 0 and greater than 0.4 (Fig. 9B and D). In addition, association between $\mathrm{ACC}_{1.0 \mathrm{~m}}$ and incidence was found for $14 \%$ of the $X$ values (Fig. 9B and D).

For ACC thresholds of 50 and 100 conidia $/ \mathrm{m}^{3}$ sampled at $1.0 \mathrm{~m}$, the prevalence of cases was 35 and 27\%, respectively. For ACC thresholds of 50 and 100 conidia/ $\mathrm{m}^{3}$ sampled at $0.35 \mathrm{~m}$, the prevalence of cases was 61 and $53 \%$, respectively. The overall accuracy of using only one sampler to estimate whether the ACC was above the thresholds of 50 and 100 conidia $/ \mathrm{m}^{3}$ was higher when sampling at $1.0 \mathrm{~m}$ with values of 0.883 and 0.923 , respectively, than sampling at $0.35 \mathrm{~m}$ with values of 0.850 and 0.841 , respectively. The sensitivity was higher when sampling at $0.35 \mathrm{~m}$ than at $1.0 \mathrm{~m}$, while specificity was higher when sampling at $1.0 \mathrm{~m}$ than at 0.35 m (Table 5).

\section{Discussion}

In the absence of formal disease risk indicators, growers generally perceive strawberry plants to be at risk for powdery mildew mainly during periods when young leaves are abundant because of their susceptibility to $P$. aphanis (4). Frequent fungicide applications are considered to be the only efficient method for managing strawberry powdery mildew. In June-bearing cultivars, postharvest periods represent a time when reducing fungicide applications represents a lower risk for strawberry growers. In the context of a more rational use of fungicides, there is a need for disease management tools, including monitoring-based tools such as airborne inoculum concentration and disease incidence thresholds. In general, monitoring-based data improve farmers' disease risk assessments and can, as a result, improve the efficacy of disease management decisions. In this study, at the scale of a strawberry field, a linear and an exponential growth relationship was found between $P$. aphanis airborne inoculum and powdery mildew severity and incidence, respectively. These results suggest that it would be possible to use either ACC or disease assessment to guide in-season disease management decisions. However, at a smaller spatial scale $\left(100 \mathrm{~m}^{2}\right)$, a significant positive association between ACC and disease incidence was found in only 54 and $14 \%$ of the sampling dates when ACC was sampled at 0.35 and $1.0 \mathrm{~m}$, respectively, suggesting that both disease risk indicators may be considered for disease management decisions. Sampling takes time and is costly, especially for airborne inoculum monitoring, which require purchase, installation, and maintenance of samplers and spore quantification from air samples. To facilitate implementation of air-

Table 4. Index of dispersion and associated statistics of the binomial and beta-binomial distributions fitted to data on strawberry powdery mildew collected in 2010 and 2011

\begin{tabular}{|c|c|c|c|c|c|c|c|}
\hline Variables & Date & $\mathbf{D}^{\mathbf{a}}$ & $\theta^{\mathbf{b}}$ & $S E(\theta)^{\mathrm{c}}$ & $P^{d}$ & $S E(p)^{\mathrm{e}}$ & LRT $^{\mathbf{f}}$ \\
\hline \multirow[t]{14}{*}{ LSD 2010} & 25 July & 0.95 & 0.00 & 0.00 & 0.01 & 0.00 & 0.00 \\
\hline & 27 July & 1.28 & 0.03 & 0.03 & 0.02 & 0.00 & 3.00 \\
\hline & 29 July & $2.74 *$ & 0.26 & 0.06 & 0.20 & 0.02 & $93.9 * * *$ \\
\hline & 10 August & $2.98 *$ & 0.34 & 0.06 & 0.44 & 0.03 & $137.4 * * *$ \\
\hline & 12 August & $1.73 *$ & 0.10 & 0.03 & 0.77 & 0.17 & $24.4 * * *$ \\
\hline & 15 August & 1.13 & 0.02 & 0.02 & 0.92 & 0.01 & 0.90 \\
\hline & 17 August & $2.8 *$ & 0.33 & 0.07 & 0.71 & 0.02 & $122.4 * * *$ \\
\hline & 19 August & $2.8^{*}$ & 0.29 & 0.06 & 0.75 & 0.02 & $107.7 * * *$ \\
\hline & 22 August & 1.29 & 0.03 & 0.02 & 0.95 & 0.01 & 3.20 \\
\hline & 31 August & 1.19 & 0.03 & 0.02 & 0.92 & 0.01 & 2.20 \\
\hline & 02 September & $2.19 *$ & 0.19 & 0.06 & 0.91 & 0.01 & $49 * * *$ \\
\hline & 05 September & 1.21 & 0.03 & 0.02 & 0.95 & 0.01 & 2.30 \\
\hline & 07 September & $1.54^{*}$ & 0.10 & 0.05 & 0.96 & 0.01 & $14.3 * * *$ \\
\hline & 09 September & $2.09^{*}$ & 0.14 & 0.08 & 0.98 & 0.01 & $20.1 * * *$ \\
\hline \multirow[t]{14}{*}{ LSD 2011} & 25 July & $6.44^{*}$ & 0.92 & 0.82 & 0.01 & 0.01 & $49.9 * * *$ \\
\hline & 27 July & $5.87 *$ & 0.14 & 0.08 & 0.02 & 0.01 & $22.6 * * *$ \\
\hline & 07 August & $2.96^{*}$ & 0.04 & 0.04 & 0.01 & 0.00 & 3.30 \\
\hline & 09 August & $9.67 *$ & 0.27 & 0.06 & 0.22 & 0.02 & $98.7 * * *$ \\
\hline & 11 August & $4.8^{*}$ & 0.12 & 0.03 & 0.26 & 0.02 & $32.7 * * *$ \\
\hline & 18 August & $8.46^{*}$ & 0.28 & 0.07 & 0.13 & 0.02 & $95.8 * * *$ \\
\hline & 21 August & $2.58 *$ & 0.24 & 0.05 & 0.32 & 0.02 & $89.1 * * *$ \\
\hline & 23 August & $6^{*}$ & 0.55 & 0.09 & 0.37 & 0.03 & $237.7 * * *$ \\
\hline & 25 August & $3.75^{*}$ & 0.02 & 0.04 & 0.56 & 0.02 & $59.5 * * *$ \\
\hline & 13 September & $2.96^{*}$ & 0.74 & 0.07 & 0.52 & 0.03 & $193.2 * * *$ \\
\hline & 15 September & $6.49 *$ & 0.16 & 0.04 & 0.45 & 0.02 & $50.5 * * *$ \\
\hline & 18 September & $2.91 *$ & 0.05 & 0.02 & 0.39 & 0.02 & $9.21 * *$ \\
\hline & 21 September & $1.98 *$ & 0.12 & 0.03 & 0.37 & 0.02 & $32.9 * * *$ \\
\hline & 23 September & $2.4^{*}$ & 0.07 & 0.02 & 0.45 & 0.02 & $15.6^{* * *}$ \\
\hline
\end{tabular}

\footnotetext{
${ }^{\mathrm{a}} \mathrm{D}$ is the index of dispersion. Values with an asterisk are significantly different from 1 based on a $\chi^{2}$ test.

$\mathrm{b} \theta$ is a parameter of the beta-binomial distribution representing a measure of heterogeneity.

c $S E(\theta)$ is the standard error on parameter $\theta$.

${ }^{\mathrm{d}} P$ is the mean estimated by the binomial distribution.

e $S E(p)$ is the standard error on parameter $p$.

${ }^{\mathrm{f}}$ Values of the likelihood ratio and level of significance according to a $\chi^{2}$ goodness-of-fit test $(* P<0.05 ; * * P<0.01 ; * * * P<0.001)$.
} 
borne inoculum monitoring practices, it is thus important to develop sampling scheme using only one or few samplers per field. This is why in this study, the reliability of using only one sampler per field was tested for classifying the field as below or above a warning (50 spores $\left./ \mathrm{m}^{3}\right)$ and an action $\left(100\right.$ spores $\left./ \mathrm{m}^{3}\right)$ threshold. From the relationship between ACC and strawberry mildew severity and incidence, these thresholds corresponded to 4 and 8 percent leaf area diseased and proportion of leaflet diseased of 0.45 and 0.60 , respectively. When sampling air at $1.0 \mathrm{~m}$, for the 28 sampling dates, the overall accuracy of using one sampler to discriminate
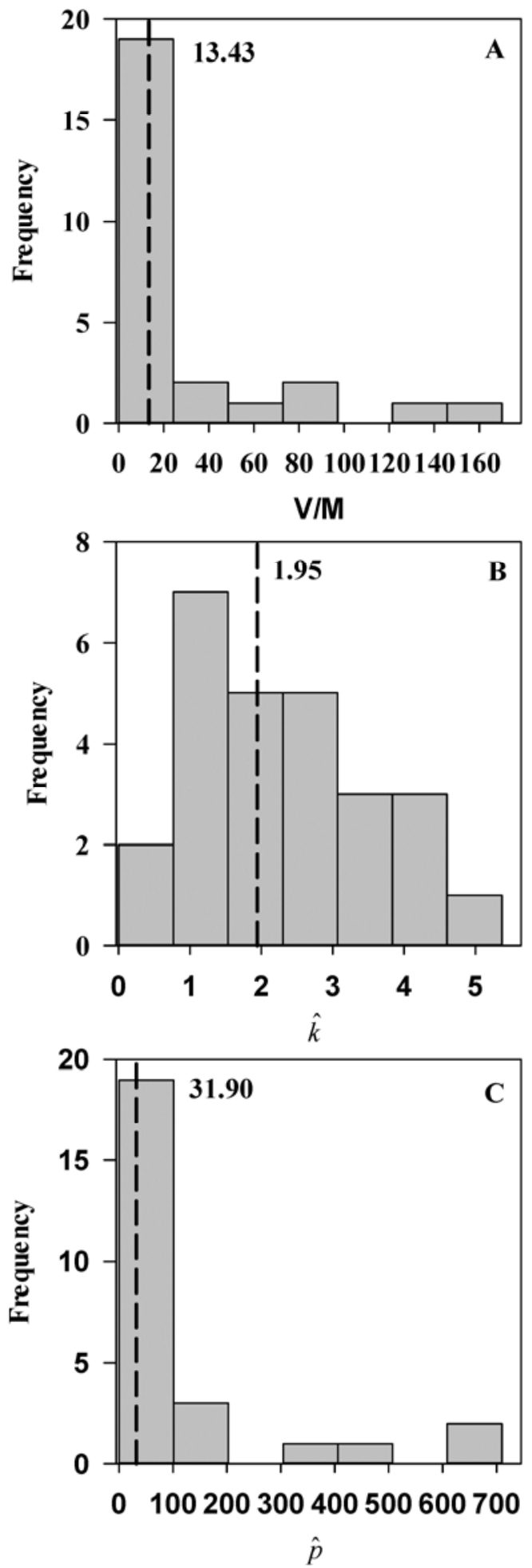

situations with airborne inoculum above or below the warning and action threshold was 0.88 and 0.92 (proportion of good discriminations), respectively. These results suggest that ACC sampling information obtained from only one sampler per field could be used to guide decisions for strawberry powdery mildew management.

Even though sampling disease incidence is generally less costly than sampling ACC, a sampling scheme is required to determine the minimum number of samples needed to make an informed decision. However, the development of sampling-based tools should be developed considering knowledge about spatial patterns.
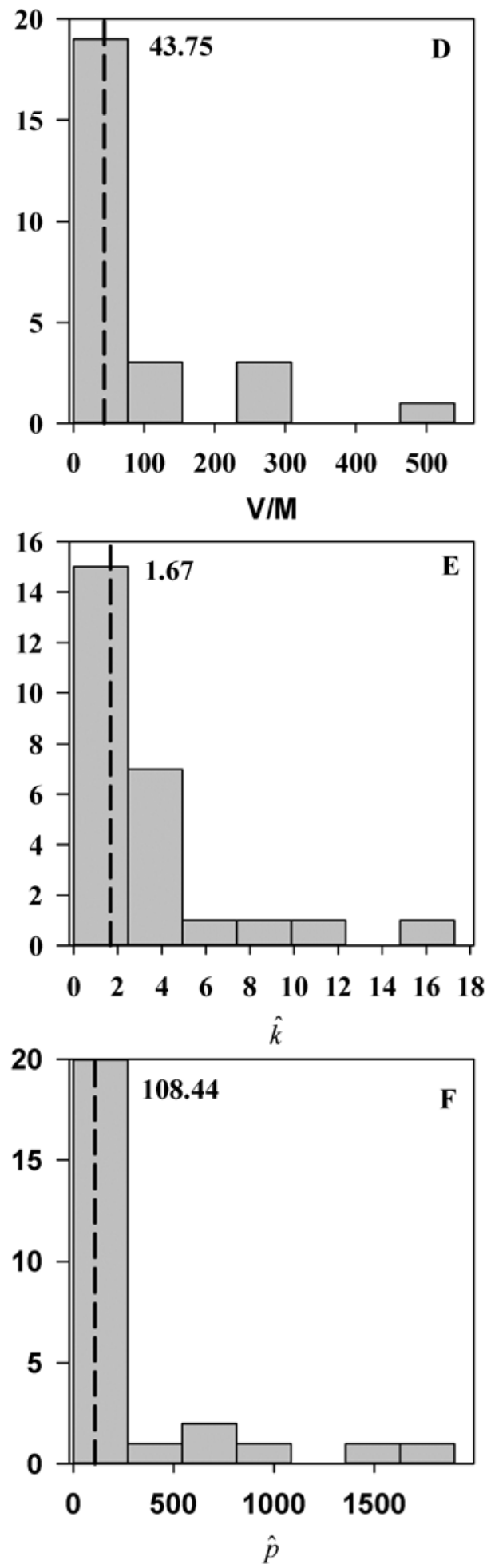

Fig. 4. Frequency distribution of the V/M ratio ( $A$ and $D)$ of the negative-binomial distribution parameters $\hat{k}(B$ and $E$ ) and $\hat{p}$ (C and $F$ ) for airborne conidium concentration at $1.0 \mathrm{~m}$ and $0.35 \mathrm{~m}$. Each vertical dashed line is the median value for the given statistic, with the numerical value indicated on the graph. 
Considering that powdery mildew on strawberry is a dynamic pathosystem that progresses in temporal and spatial scales, this study formally described the spatial pattern of airborne inocula and powdery mildew incidence.

Despite the few reports available on the spatial distribution of fungal airborne inocula of pathogens such as those causing powdery mildews, their distribution is generally considered to be more
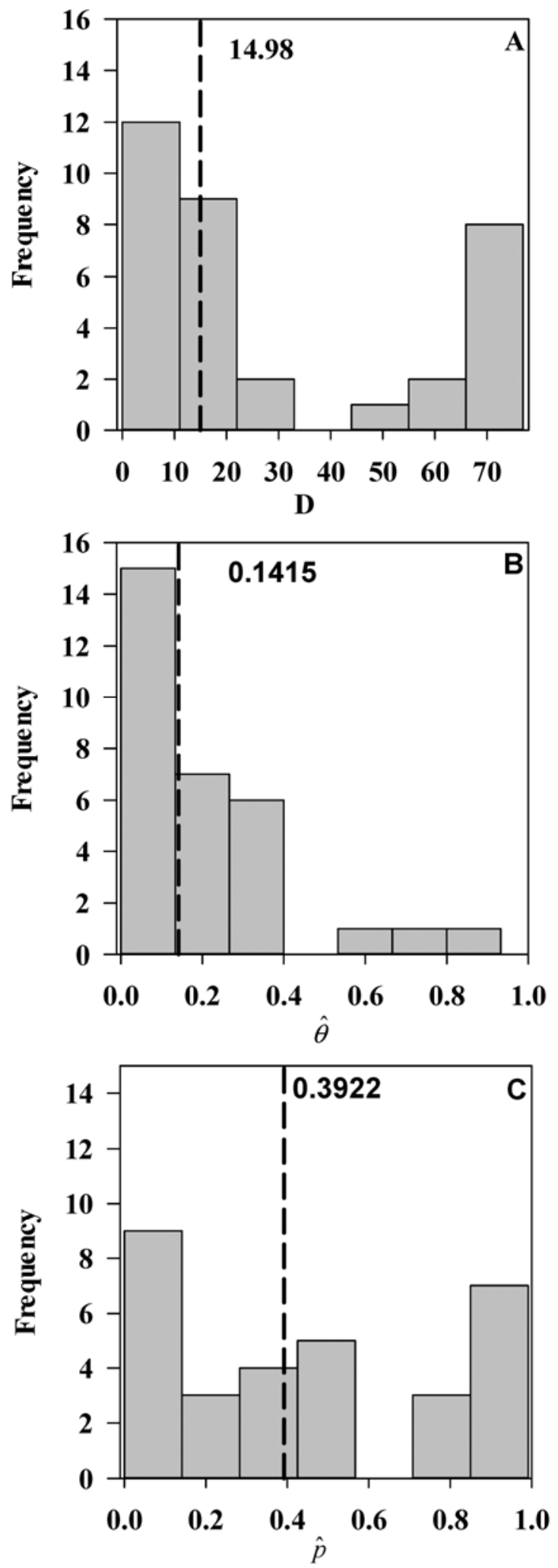

Fig. 5. Frequency distribution of the beta-binomial distribution parameters $\mathbf{A}, D$, $\mathbf{B}, \hat{\theta}$, and $\mathbf{C}, \hat{p}$ for strawberry powdery mildew incidence. Vertical dashed line is median value for the given statistic, with the numerical value indicated on the graph.
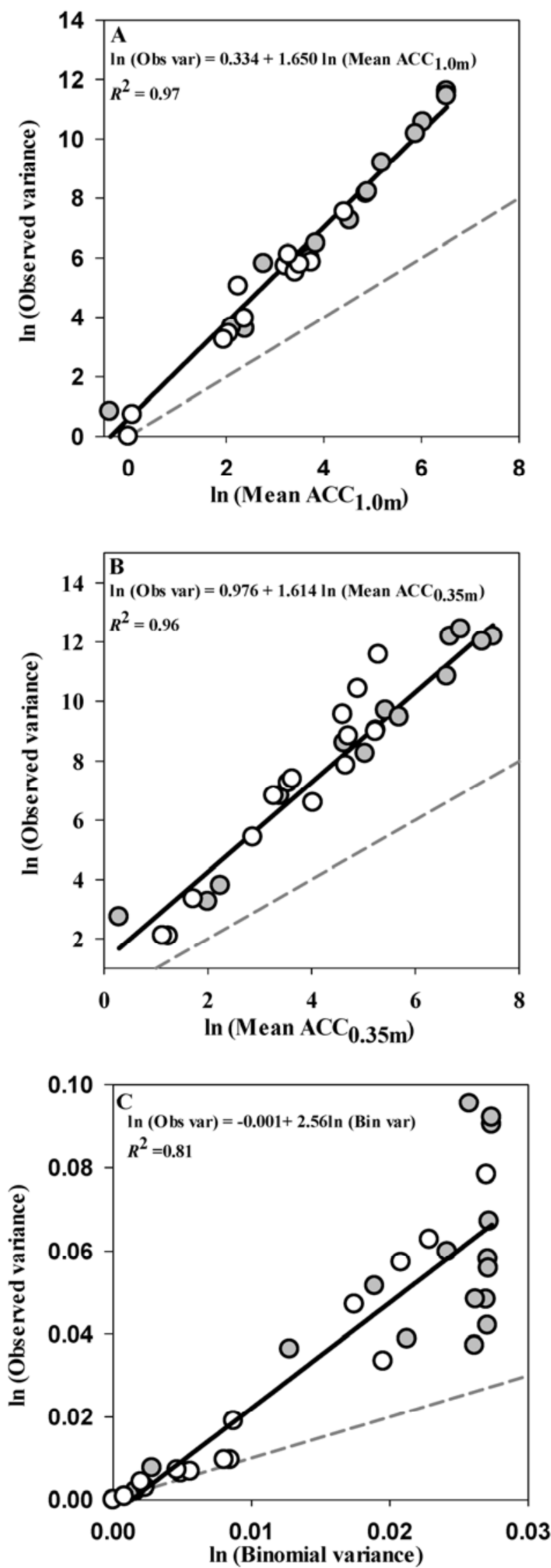

Fig. 6. Relationship between logarithm of the observed variance and logarithm of A, mean airborne conidium concentration at $1.0 \mathrm{~m}$ above the ground $\left(\mathrm{ACC}_{1.0 \mathrm{~m}}\right), \mathbf{B}$, mean $\mathrm{ACC}$ at $0.35 \mathrm{~m}$ above the ground $\left(\mathrm{ACC}_{0.35 \mathrm{~m}}\right)$, and $\mathrm{C}$, powdery mildew incidence. Gray and white circles represent observations taken in 2010 and 2011, respectively. Solid line represents adjusted linear regression, dotted line represents $95 \%$ confidence interval, and dashed line represents a straight line with a slope of 1 . 
or less homogeneous. For P. aphanis, the analysis of the V/M ratios shows that ACC measured at both 0.35 and $1.0 \mathrm{~m}$ from the ground can be considered heterogeneous, given that, for the majority of the sampling dates, the V/M ratios were significantly greater than 1 . These results were further confirmed by the distribution analysis, which showed that the negative binomial distribution fits the data best for 26 of the 28 sampling dates. Moreover, based on the analysis of the power law relationships among sampling dates, heteroge- neity increased with increasing airborne inoculum concentration. These results are supported by findings that Venturia inaequalis ascospores and Botrytis squamosa conidia, respectively, are heterogeneously distributed in commercial fields $(7,8)$.

Unlike airborne inoculum concentrations, spatial distributions of several powdery mildews have been studied (14,25-27). In the present study, the spatial distribution of strawberry powdery mildew was characterized as weakly heterogeneous. The V/M ratio

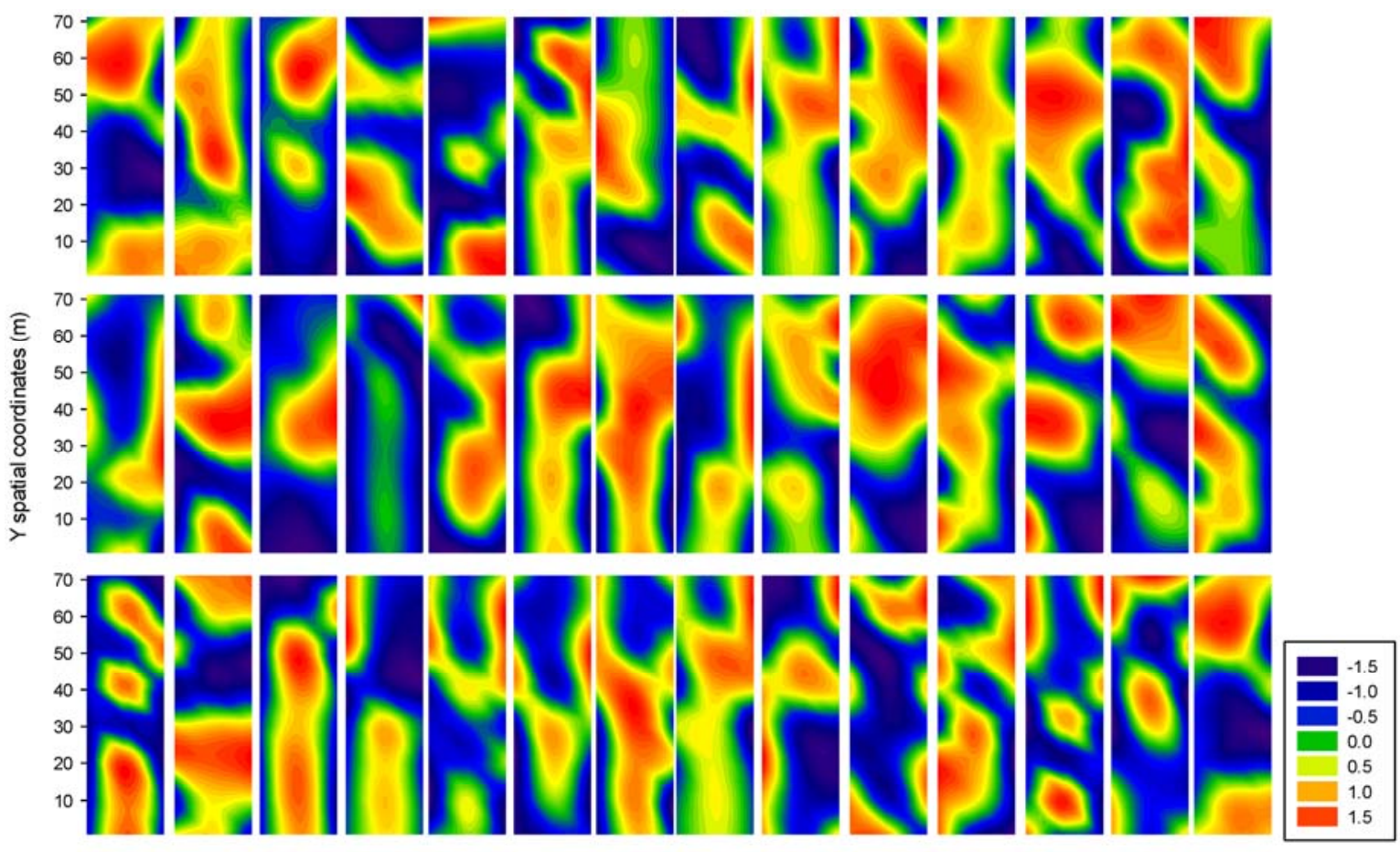

$X$ spatial coordinates $(m)$

Fig. 7. Contour plot of the spatial analysis by distance indices (SADIE) clustering index for airborne conidium concentration $\mathbf{A}, \mathrm{ACC}_{1.0 \mathrm{~m}}, \mathbf{B}, \mathrm{ACC}_{0.35 \mathrm{~m}}$, and $\mathbf{C}$, disease incidence for the 14 assessment dates in 2010.

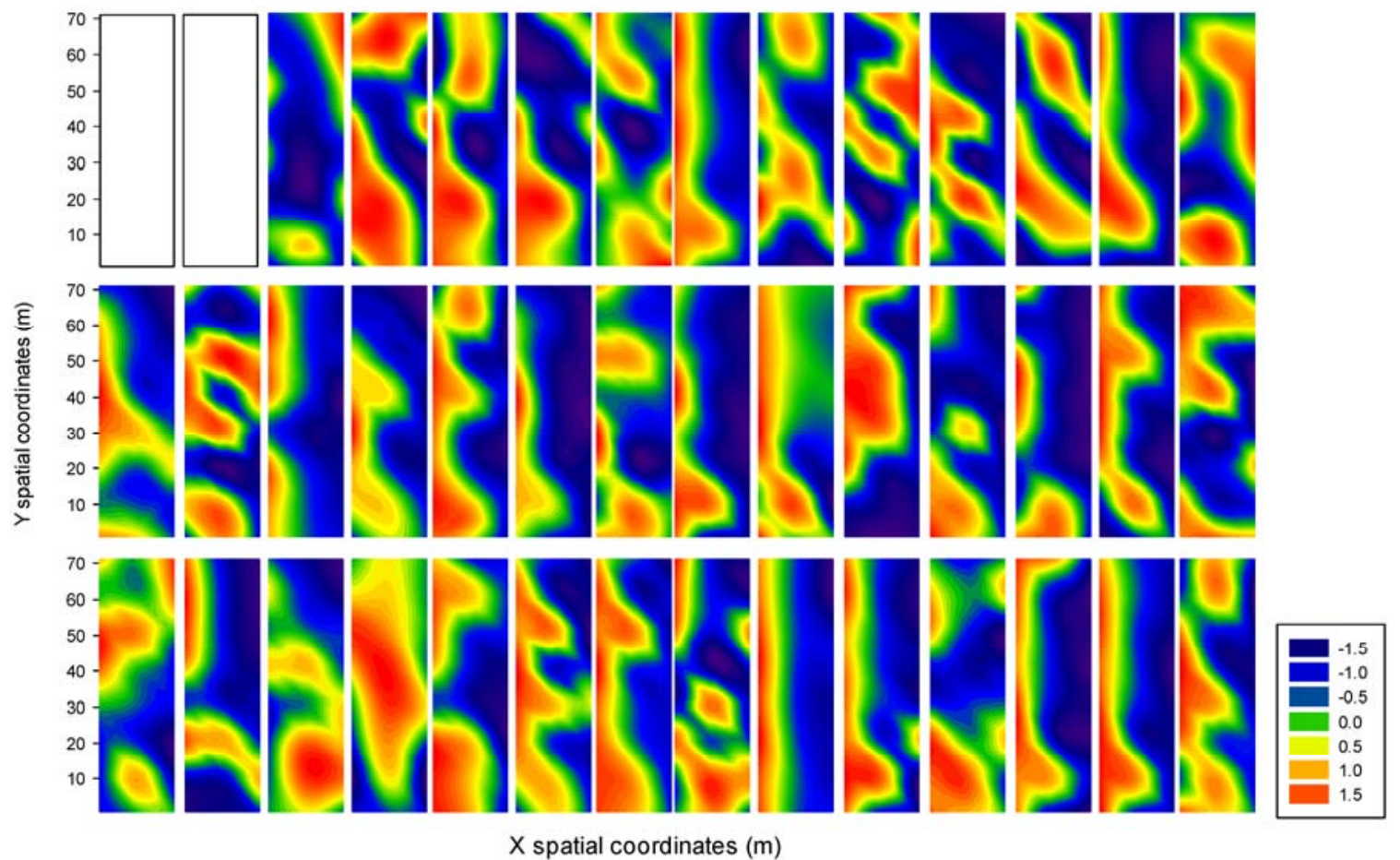

Fig. 8. Contour plot of the spatial analysis by distance indices (SADIE) clustering index for airborne conidium concentration $\mathbf{A}, \mathrm{ACC}_{1.0 \mathrm{~m}}, \mathbf{B}, \mathrm{ACC}_{0.35 \mathrm{~m}}$, and $\mathbf{C}$, disease incidence for the 14 assessment dates in 2011. 
was significantly greater than 1 for only $28 \%$ of the sampling dates, indicating some level of heterogeneity. This observation was further supported by the results of the distribution analysis, given that only $28 \%$ of the data sets fit the negative binomial distribution better than the Poisson distribution. In addition, the $b$ and $A_{x}$ parameters of Taylor's power law did not differ from 1, indicating that the overall spatial pattern of strawberry powdery mildew cannot be distinguished from a random pattern. Similar to that of strawberry powdery mildew, the spatial distribution of powdery mildews on hops are considered to vary from nearly random to weakly heterogeneous, whereas powdery mildew on apple is considered to be random in terms of the number of mildewed leaves per shoot, although some heterogeneity has been found in mildew colonies $(14,25,26)$.

The development of new sampling tools based on airborne inoculum or disease incidence requires an understanding of the intrinsic spatial structure of the epiphytotic. When the spatial location of each sampling device was taken into account, the results show that spatial variation increased as the disease progressed with time. As a result, the shapes of the disease progress curves for airborne inoculum at both heights and for mildew incidence are similar, suggesting that there was a relationship between airborne inocula and disease incidence. With the SADIE approach, the results were similar to those obtained with the V/M ratio analysis and with the distribution fitting. However, the aggregation indices $\left(I_{a}\right)$ varied around a value of 0.5 , indicating a weak spatial aggregation. These results suggest that, in the case of strawberry powdery mildew, the heterogeneity of airborne inoculum and disease incidence cannot be associated with clear foci or distinguish aggregates. Similar to hop powdery mildew, these results suggest the epiphytotic may be driven by well-distributed and/or highly dispersible inoculum (25).

The SADIE procedure also allows the spatial association or correlation between airborne inoculum and disease incidence to be assessed. A positive association between both airborne inoculum regardless of the sampling height and disease incidence was detected for most of the sampling dates, but the association was more
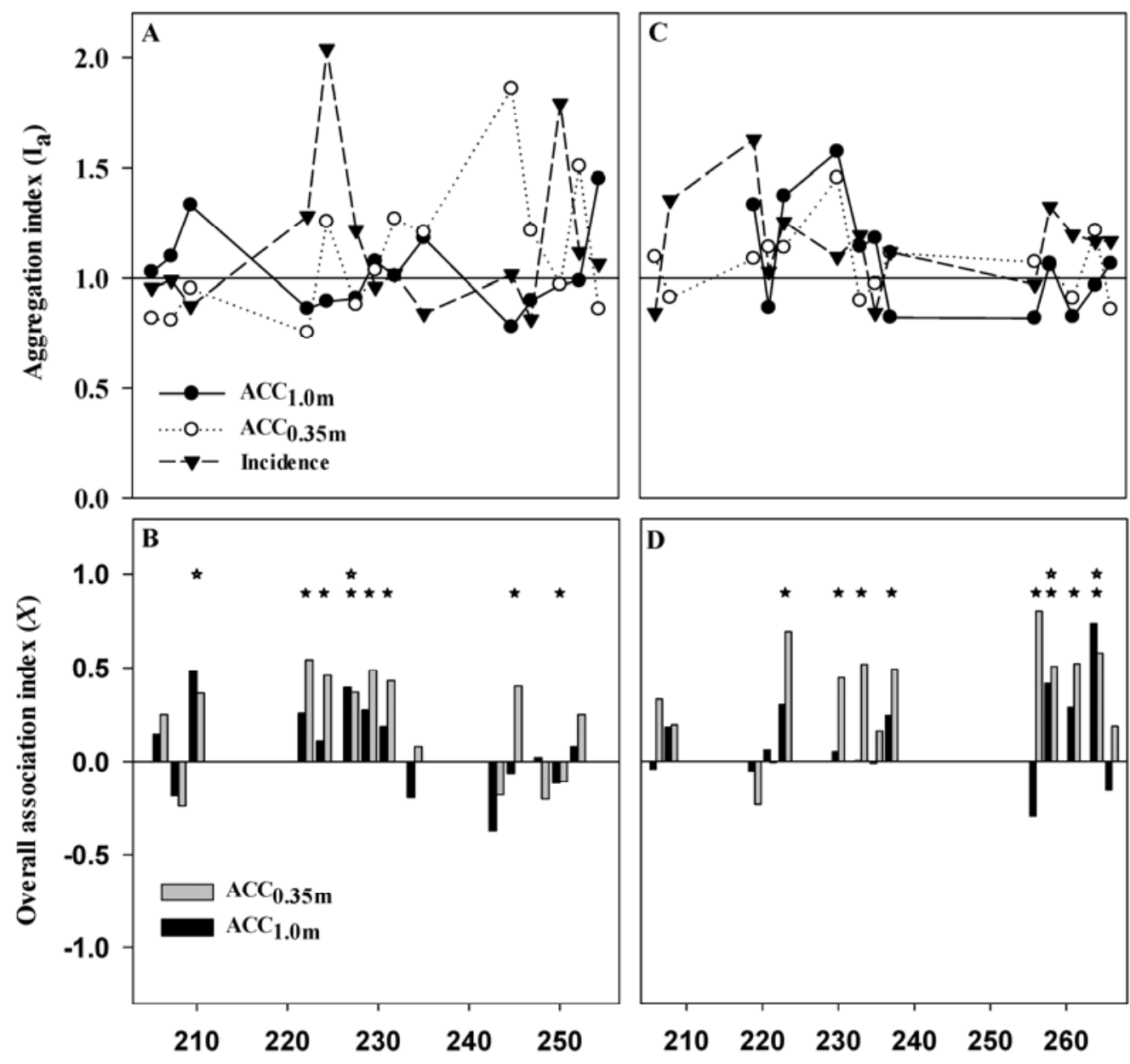

Day of the year

Day of the year

Fig. 9. Spatial aggregation index $\left(I_{a}\right)$ measured with spatial analysis by distance indices (SADIE) for airborne conidium concentration at $1.0 \mathrm{~m}$ above the ground $\left(A C C_{1.0 m}\right)$, at $0.35 \mathrm{~m}$ above the ground $\left(\mathrm{ACC}_{0.35 \mathrm{~m}}\right)$, and disease incidence expressed as a number of leaflet diseased for Podosphaera aphanis in A, 2010 and $\mathbf{C}, 2011$, and spatial association index $(X)$ measured by SADIE between $\mathrm{ACC}_{1.0 \mathrm{~m}}$ and powdery mildew incidence (black bars) and between $\mathrm{ACC}_{0.35 \mathrm{~m}}$ and powdery mildew incidence (gray bars) for B, 2010 and D, 2011.

Table 5. Overall accuracy, sensitivity, and specificity of one sampler for predicting whether overall mean Podosphaera aphanis airborne conidia concentration is at, above, or below an action threshold of 50 conidia $/ \mathrm{m}^{3}$ or $100 \mathrm{conidia} / \mathrm{m}^{3}$

\begin{tabular}{lcccc}
\hline Height $(\mathbf{m})$ & Threshold $\left(\mathbf{c o n i d i a} / \mathbf{m}^{\mathbf{3}}\right)$ & Overall accuracy & Sensitivity & Specificity \\
\hline 1.0 & 50 & 0.883 & 0.807 & 0.928 \\
& 100 & 0.923 & 0.885 & 0.936 \\
0.35 & 50 & 0.850 & 0.918 & 0.767 \\
& 100 & 0.841 & 0.926 & 0.773 \\
\hline
\end{tabular}


often significant between disease incidence and airborne inoculum sampled at $0.35 \mathrm{~m}$ from the ground. The magnitudes of the estimated $X$ were similar to those found in other studies (7).

The selection of weather variables for the prediction of risk of strawberry powdery mildew remains variable. Both disease incidence and airborne inoculum are directly related to disease risk and hence could be used to determine if a management action is required. However, disease incidence and airborne inoculum thresholds for management action, such as fungicide application, will need to be developed for both pre- and postharvest periods. In addition, sampling schemes will be needed to determine how many samples are required to estimate mean strawberry mildew incidence.

\section{Acknowledgments}

We are grateful to all the summer students and the scouts from the PRISME Consortium for their technical assistance. This work was financially supported by the Quebec Department of Agriculture, Fisheries and Food's PrimeVert program and by Agriculture and Agri-Food Canada. The contribution of $\mathrm{H}$. Van der Heyden, M. Lefebvre, L. Roberge, and L. Brodeur to this work was partially supported by the Compagnie de Recherche Phytodata Inc.

\section{Literature Cited}

1. Amsalem, L., Freeman, S., Rav-David, D., Nitzani, Y., Sztejnberg, A., Pertot, I., and Elad, Y. 2006. Effect of climatic factors on powdery mildew caused by Sphaerotheca macularis f. sp. fragariae on strawberry. Eur. J. Plant Pathol. 114:283-292.

2. Berrie, A. M., and Burgess, C. M. 1997. The effect of post-harvest epidemics of powdery mildew on yield and growth of strawberry cv. Elsanta. Proc. 3rd Int. Strawberry Sympos. Acta Hortic. 439:791-798.

3. Blanco, C., de los Santos, B., Barrau, C., Arroyo, F. T., Porras, M., and Romero, F. 2004. Relationship among concentrations of Sphaerotheca macularis conidia in the air, environmental conditions, and the incidence of powdery mildew in strawberry. Plant Dis. 88:878-881.

4. Carisse, O., and Bouchard, J. 2010. Age-related susceptibility of strawberry leaves and berries to infection by Podosphaera aphanis. Crop Prot. 29:969978.

5. Carisse, O., Lefebvre, A., Van der Heyden, H., Roberge, L., and Brodeur, L. 2013. Analysis of incidence-severity relationships for strawberry powdery mildew as influenced by cultivar, cultivar type, and production systems. Plant Dis. 97:354-362.

6. Carisse, O., Morissette-Thomas, V., and Van der Heyden, H. 2013. Lagged association between powdery mildew leaf severity, airborne inoculum, weather, and crop losses in strawberry. Phytopathology 103:811-821.

7. Carisse, O., Savary, S., and Willocquet, L. 2008. Spatiotemporal relationships between disease development and airborne inoculum in unmanaged and managed Botrytis leaf blight epidemics. Phytopathology 98:38-44.

8. Charest, J., Dewdney, M., Paulitz, T. C., Philion, V., and Carisse, O. 2002. Spatial distribution of Venturia inaequalis airborne ascospores in orchards. Phytopathology 92:769-779.
9. Darnell, R. L., Cantliffe, D. J., Kirschbaum, D. S., and Chandler, C. K 2003. The physiology of flowering in strawberry. Hortic. Rev. 28:325-349.

10. Dutilleul, P. 1993. Modifying the $t$ test for assessing the correlation between two spatial processes. Biometrics 49:305-314.

11. Dutilleul, P. 2011. Spatio-temporal heterogeneity: Concepts and analyses. Cambridge University Press, Cambridge, UK.

12. Gadoury, D. M., Asalf, B., Heidenreich, M. C., Herrero, M. L., Welser, M. J., Seem, R. C., Tronsmo, A. M., and Stensvand, A. 2010. Initiation, development, and survival of cleistothecia of Podosphaera aphanis and their role in the epidemiology of strawberry powdery mildew. Phytopathology 100:246-251

13. Gent, D. H., Farnsworth, J. L., and Johnson, D. A. 2012. Spatial analysis and incidence-density relationships for downy mildew on hop. Plant Pathol. 61:37-47.

14. Gent, D. H., Mahaffee, W. F., and Turechek, W. W. 2006. Spatial heterogeneity of the incidence of powdery mildew on hop cones. Plant Dis. 90:14331440 .

15. Hughes, G. 2011. Applications of Information Theory to Epidemiology. American Phytopathological Society, St. Paul, MN.

16. Li, B., Madden, L. V., and Xu, X. 2012. Spatial analysis by distance indices: An alternative local clustering index for studying spatial patterns. Methods Ecol. Evol. 3:368-377.

17. Maas, J. L. 1998. Compendium of Strawberry Diseases. 2nd ed. American Phytopathological Society, St. Paul, MN.

18. Madden, L. V., Hughes, G., and van den Bosch, F. 2007. The Study of Plant Disease Epidemics. American Phytopathological Society, St. Paul, MN.

19. Miller, T. C., Gubler, W. D., Geng, S., and Rizzo, D. M. 2003. Effects of temperature and water vapor pressure on conidial germination and lesion expansion of Sphaerotheca macularis f. sp. fragariae. Plant Dis. 87:484492.

20. Nelson, M. D., Gubler, W. D., and Shaw, D. V. 1995. Inheritance of powdery mildew resistance in greenhouse-grown versus field-grown California strawberry progenies. Phytopathology 85:421-424.

21. Perry, J. N. 1998. Measures of spatial pattern for counts. Ecology 79:1008 1017.

22. Sombardier, A., Savary, S., Blancard, D., Jolivet, J., and Willocquet, L. 2009. Effects of leaf surface and temperature on monocyclic processes in Podosphaera aphanis, causing powdery mildew of strawberry. Can. J. Plant Pathol. 31:439-448.

23. Statistics Canada, 2012. Fruit and Vegetable Production (Catalogue no. 22003-X, vol. 80, no. 2)

24. Turechek, W. W., and Madden, L. V. 1999. Spatial pattern analysis of strawberry leaf blight in perennial production systems. Phytopathology 89:421433.

25. Turechek, W. W., and Mahaffee, W. F. 2004. Spatial pattern analysis of hop powdery mildew in the Pacific Northwest: Implications for sampling. Phytopathology 94:1116-1128.

26. Xiao, C. L., Chandler, C. K., Price, J. F., Duval, J. R., Mertely, J. C., and Legard, D. E. 2001. Comparison of epidemics of Botrytis fruit rot and powdery mildew of strawberry in large plastic tunnel and field production systems. Plant Dis. 85:901-909.

27. Xu, X.-M., and Madden, L. V. 2002. Incidence and density relationships of powdery mildew on apple. Phytopathology 92:1005-1014. 